OPEN ACCESS

Edited by:

Joerg Graf,

University of Connecticut, USA

Reviewed by:

Erik Cordes,

Temple University, USA

Raquel Peixoto,

Federal University of Rio de Janeiro,

Brazil

*Correspondence: Christina A. Kellogg ckellogg@usgs.gov

Specialty section: This article was submitted to Microbial Symbioses, a section of the journal Frontiers in Microbiology

Received: 19 January 2017 Accepted: 18 April 2017

Published: 04 May 2017

Citation:

Kellogg CA, Goldsmith $D B$ and

Gray MA (2017) Biogeographic

Comparison of Lophelia-Associated Bacterial Communities in the Western Atlantic Reveals Conserved Core Microbiome. Front. Microbiol. 8:796.

doi: 10.3389/fmicb.2017.00796

\section{Biogeographic Comparison of Lophelia-Associated Bacterial Communities in the Western Atlantic Reveals Conserved Core Microbiome}

\author{
Christina A. Kellogg *, Dawn B. Goldsmith and Michael A. Gray \\ St. Petersburg Coastal and Marine Science Center, United States Geological Survey, St. Petersburg, FL, USA
}

Over the last decade, publications on deep-sea corals have tripled. Most attention has been paid to Lophelia pertusa, a globally distributed scleractinian coral that creates critical three-dimensional habitat in the deep ocean. The bacterial community associated with $L$. pertusa has been previously described by a number of studies at sites in the Mediterranean Sea, Norwegian fjords, off Great Britain, and in the Gulf of Mexico (GOM). However, use of different methodologies prevents direct comparisons in most cases. Our objectives were to address intra-regional variation and to identify any conserved bacterial core community. We collected samples from three distinct colonies of $L$. pertusa at each of four locations within the western Atlantic: three sites within the GOM and one off the east coast of the United States. Amplicon libraries of $16 \mathrm{~S}$ rRNA genes were generated using primers targeting the V4-V5 hypervariable region and 454 pyrosequencing. The dominant phylum was Proteobacteria (75-96\%). At the family level, $80-95 \%$ of each sample was comprised of five groups: Pirellulaceae, Pseudonocardiaceae, Rhodobacteraceae, Sphingomonadaceae, and unclassified Oceanospirillales. Principal coordinate analysis based on weighted UniFrac distances showed a clear distinction between the GOM and Atlantic samples. Interestingly, the replicate samples from each location did not always cluster together, indicating there is not a strong site-specific influence. The core bacterial community, conserved in $100 \%$ of the samples, was dominated by the operational taxonomic units of genera Novosphingobium and Pseudonocardia, both known degraders of aromatic hydrocarbons. The sequence of another core member, Propionibacterium, was also found in prior studies of $L$. pertusa from Norway and Great Britain, suggesting a role as a conserved symbiont. By examining more than 40,000 sequences per sample, we found that GOM samples were dominated by the identified conserved core sequences, whereas open Atlantic samples had a much higher proportion of locally consistent bacteria. Further, predictive functional profiling highlights the potential for the L. pertusa microbiome to contribute to chemoautotrophy, nutrient cycling, and antibiotic production.

Keywords: deep-sea corals, microbiome, scleractinian, amplicon sequencing, microbial diversity, Gulf of Mexico 


\section{INTRODUCTION}

Over the last decade, the number of publications on deep-sea corals has tripled. This increase in focus has been driven mainly by conservation concerns due to the co-location of many of these cold-water coral habitats with areas where commercial fishing or oil and gas drilling are occurring. These coral habitats form biodiversity hot spots in the deep ocean (Mortensen et al., 1995) and are of interest for a variety of reasons ranging from bioprospecting (Maxwell, 2005), to interpreting paleoclimate conditions using geochemical markers in the coral skeletons (Williams et al., 2006). The lion's share of attention has been paid to Lophelia pertusa, a globally distributed scleractinian coral that creates critical three-dimensional habitat for a large assortment of other invertebrate and vertebrate species (Cordes et al., 2008). This coral species is azooxanthellate, but forms branching colonies that can fuse together to form large mounds. These coral mounds tend to occur on high points in areas of strong current, to facilitate capture-feeding by the coral.

Nutrition is an area of key interest when studying the microbiomes of deep-sea corals. These corals do not have photosynthetic algal partners like tropical corals, so heterotrophic bacterial associates have been hypothesized to play a larger role in nutrient acquisition and cycling (Neulinger et al., 2008; Kellogg et al., 2016; Lawler et al., 2016). A recent study of L. pertusa using isotope tracer evidence was able to show nitrogen cycling and transfer of fixed nitrogen and inorganic carbon into the coral tissue (Middelburg et al., 2015). However, the specific microbes involved in the nitrogen cycling remain to be identified.

The bacterial community associated with L. pertusa has been described by a number of molecular and culture-based methods (Yakimov et al., 2006; Neulinger et al., 2008, 2009; Hansson et al., 2009; Kellogg et al., 2009; Schöttner et al., 2009; Galkiewicz et al., 2011; Emblem et al., 2012; van Bleijswijk et al., 2015; Meistertzheim et al., 2016). While these studies have been geographically diverse, including the Mediterranean Sea (Yakimov et al., 2006; Meistertzheim et al., 2016), Norwegian fjords (Neulinger et al., 2008, 2009; Schöttner et al., 2009; Emblem et al., 2012), Rockall Banks (Hansson et al., 2009; van Bleijswijk et al., 2015) and the Gulf of Mexico (Kellogg et al., 2009; Galkiewicz et al., 2011), the use of different methodologies prevents direct data comparisons in most cases. A key exception is $16 \mathrm{~S}$ rRNA gene clone library studies conducted with almost identical methods on $L$. pertusa from the Trondheimsfjord in Norway (Neulinger et al., 2008) and the Gulf of Mexico (Kellogg et al., 2009). Comparing these datasets revealed conserved sequences that were postulated to be Lophelia-specific bacterial symbionts (Kellogg et al., 2009).

However, comparisons of these datasets (Neulinger et al., 2008; Kellogg et al., 2009) also indicate that there are differences between the Lophelia-associated bacterial communities across the Atlantic. This may be due to the small sample size (less than 1000 $16 \mathrm{~S}$ rRNA gene sequences between the two papers), but could be genuine variation. On a smaller geographic scale, bacterial community differences have been detected between L pertusa colonies from sites as close as $3.9 \mathrm{~km}$ in Norway (by T-RFLP profiles; Neulinger et al., 2008) and between sites separated by $36.8 \mathrm{~km}$ in the Gulf of Mexico (by $16 \mathrm{~S}$ rRNA gene clone libraries; Kellogg et al., 2009). Overall, these results support a new paradigm from the shallow-water coral literature: that coral microbiomes consist of three components-(1) a small conserved core of microbial symbionts, (2) a larger group of regionally conserved bacteria specific to a geographic site, depth range, etc., and (3) an environmentally variable bacterial community (Hernandez-Agreda et al., 2016; van de Water et al., 2016).

We hypothesize that there is a conserved core of bacterial symbionts held in common by all L. pertusa, while the rest of the bacterial community varies depending on local environmental characteristics such as dominant food source, benthic community structure, or water mass parameters. Our objective was to address this issue of intra-regional variation with deep pyrosequencing. To do this, we collected L. pertusa from three locations within the Gulf of Mexico and one Atlantic location off the east coast of Florida (Figure 1). We analyzed the bacterial communities from three biological replicates (unique coral colonies) at each location in order to examine within-site as well as between-site variation. In an attempt to elucidate the potential functional roles of $L$. pertusa's bacteria associates, we have employed functional profile prediction (Langille et al., 2013). This technique uses a reference phylogeny of completed bacterial genomes to predict the genomic copy number of each gene family, and those gene families have been linked with experimental evidence of functionality. While the quality of the predictions is directly related to how many relevant environmental bacterial genomes are available in the database, this technique has been increasingly applied to temperate and tropical coral systems (Ainsworth et al., 2015; Morrow et al., 2015; Rubio-Portillo et al., 2016; van de Water et al., 2016; Zaneveld et al., 2016).

\section{MATERIALS AND METHODS}

\section{Sample Sites and Collections}

Although both orange and white color morphs are common in European waters (Neulinger et al., 2008), only white L. pertusa was observed and collected during this study. Three biological replicates (individual colonies of $L$. pertusa) were sampled at each of four sites: Viosca Knoll 906 (VK906), Viosca Knoll 826 (VK826), West Florida Slope 1 (WFS1), and Atlantic 1 (ATL1) (Figure 1). Location, temperature, salinity, and depth were recorded for each sample (Table 1). There was a depth gradient across the sites, becoming deeper west to east, increasing from 397 to $751 \mathrm{~m}$ (Table 1). Note that our VK906, the shallowest site, is nearer to a site known was VK862S (CSA International Inc., 2007) and is colloquially known as "Harry's Reef." This should not be confused with the VK906 site known as "Robert's Reef" which has an extensive coral mound (Lunden et al., 2013). Our VK906 site featured isolated colonies of L. pertusa with frailer skeletons ("gracilis" morphotype; Brooke et al., 2007). VK826 and WFS1 had extensive thickets of L. pertusa with heavily calcified skeletons ("brachycephala" morphotype; Brooke et al., 2007). ATL1 had clusters of L. pertusa colonies with several meters of dead coral or rubble between the live corals. 


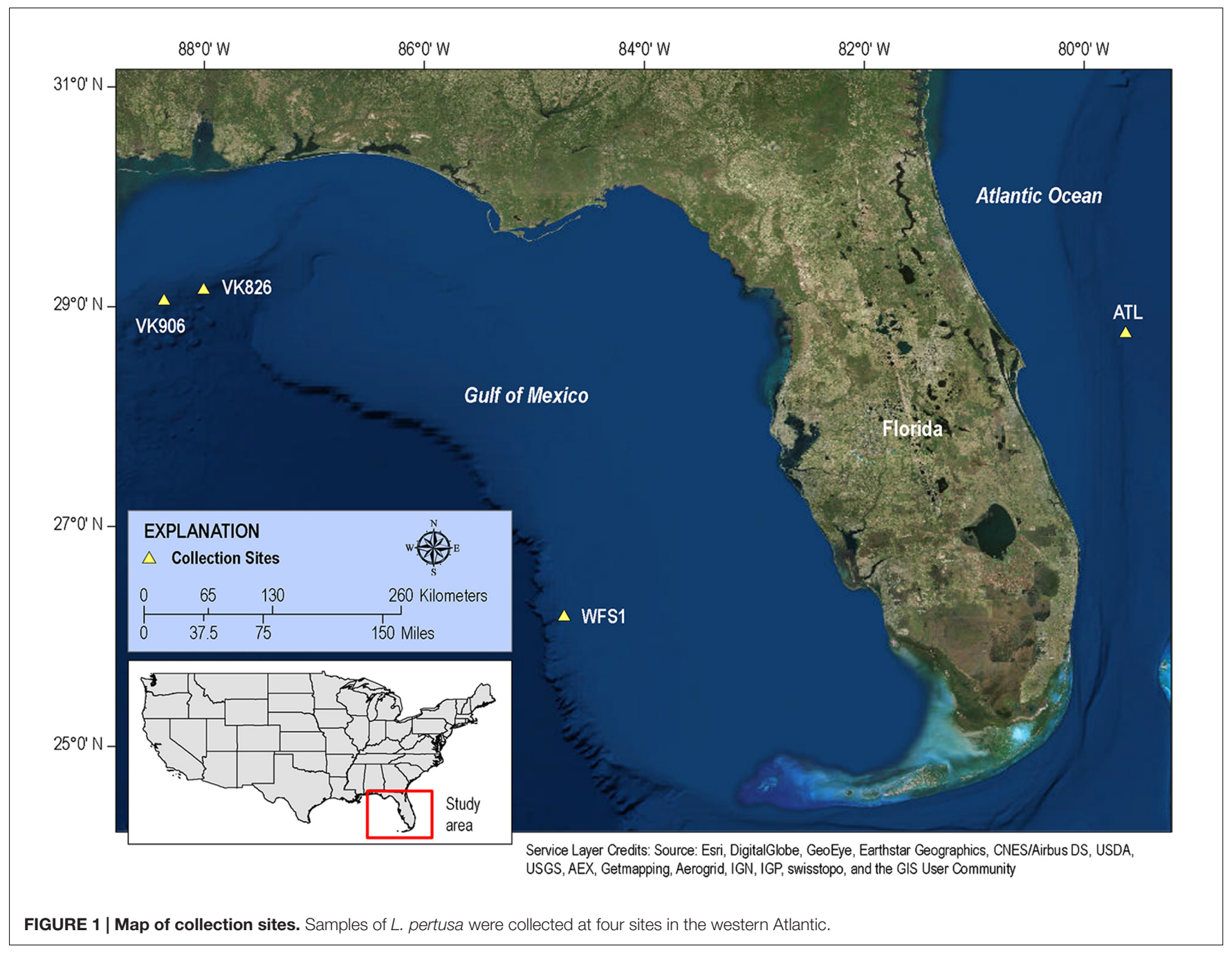

TABLE 1 | Sample collection site and associated environmental data for $L$. pertusa coral collections.

\begin{tabular}{|c|c|c|c|c|c|c|c|c|c|}
\hline Sample ID & Site & Location & Month & Year & Depth (m) & Temp $\left({ }^{\circ} \mathbf{C}\right)$ & Salinity & Latitude & Longitude \\
\hline ROV02Q2 & VK826 & Gulf of Mexico & September & 2010 & 490 & 8.2 & 35.0 & 29.169867 & 88.013117 \\
\hline ROV06Q3 & VK906 & Gulf of Mexico & September & 2010 & 413 & 11.0 & 35.3 & 29.071167 & 88.375190 \\
\hline ROV05Q2 & VK906 & Gulf of Mexico & September & 2010 & 403 & 9.6 & 35.1 & 29.073780 & 88.379637 \\
\hline $3731 \mathrm{~K} 3$ & VK906 & Gulf of Mexico & September & 2009 & 397 & 10.7 & 35.3 & 29.068632 & 88.377852 \\
\hline ROV09Q1 & WFS1 & Gulf of Mexico & September & 2010 & 543 & 8.3 & 35.0 & 26.204765 & 84.731838 \\
\hline ROV07Q1 & WFS1 & Gulf of Mexico & September & 2010 & 504 & 8.2 & 35.0 & 26.207422 & 84.727083 \\
\hline 3705K6 & ATL & Atlantic & August & 2009 & 743 & 7.5 & 35.0 & 28.775677 & 79.616043 \\
\hline $3705 \mathrm{KIO}$ & ATL & Atlantic & August & 2009 & 743 & 7.5 & 35.0 & 28.775783 & 79.615905 \\
\hline 3705K3 & ATL & Atlantic & August & 2009 & 751 & 7.5 & 35.0 & 28.775843 & 79.616130 \\
\hline
\end{tabular}

Shading to show groups of biological replicates from the same site at a glance.

Samples with names prefixed by 3705 or 3731 were collected using the Johnson-Sea-Link submersible (Harbor Branch Oceanographic Institution) using the Kellogg sampler (Kellogg et al., 2009) during cruises in August and September
2009. Briefly, the sampler's individual compartments were cleaned at the surface using ethanol, filled with sterile deionized water and sealed. Coral branches were collected and placed into the containers after ambient seawater evacuated the freshwater, 
and then the containers were re-sealed at depth. Samples with names beginning with ROV0 were collected using the remotelyoperated vehicle (ROV) Kraken II (University of Connecticut) during a research cruise in September 2010. The ROV carried several individual polyvinylchloride (PVC) quivers that were cleaned with ethanol, filled with sterile deionized water and sealed at the surface with rubber stoppers. Immediately prior to collection, a quiver was opened, the sample placed inside, and the quiver sealed before the ROV continued its deployment. Upon return to the surface, all $L$. pertusa samples were transferred to sterile tubes, covered in RNAlater (Life Technologies, Grand Island, NY, USA), and incubated overnight at $4^{\circ} \mathrm{C}$ to allow the preservative to permeate the coral tissues before transfer to $-20^{\circ} \mathrm{C}$ for long-term storage.

\section{Nucleic Acid Extraction}

All samples from all sites were extracted as follows. The coral fragment was removed from RNAlater using sterile forceps and placed into a sterile aluminum weigh boat in a laminar flow hood. Two polyps from each coral sample (taken from the middle or tip of the branch to avoid any potential contamination at the base where the sampling claw was in contact with the coral) were combined to homogenize the variability of the bacterial community that may exist between polyps (Hansson et al., 2009; Meistertzheim et al., 2016). The calyces containing polyps of L. pertusa were broken from the main branch with sterile pliers and placed into separate sterile aluminum dishes by sample. The calyces were cracked open with a sterile hammer and the tissue was removed from the skeleton using an airbrush with sterile phosphate buffered saline (PBS) and sterile forceps, using the minimum volume of PBS necessary per sample (ca. 200-500 $\mu \mathrm{l}$ ). While mainly tissue, the samples may have entrained some coral mucus since no specific effort was made to exclude it. DNA was extracted from the samples using the MO BIO PowerPlant DNA Isolation Kit (MO BIO Laboratories; Carlsbad, CA, USA) following the suggested modifications in Sunagawa et al. (2010). Briefly, approximately $50 \mathrm{mg}$ aliquots of the tissue slurry from each sample were processed with the addition of a lysozyme step and additional smaller beads to expedite physical lysis. Three extractions were done per coral sample (for a total of 36 extractions) and then recombined by sample after elution of the DNA from the spin column (resulting in 12 DNA samples, one per coral). The DNA samples were quantified with Quanti-iT PicoGreen dsDNA Assay Kit (Invitrogen; Eugene, OR, USA) per the manufacturer's protocol.

\section{S rRNA Gene Pyrosequencing}

DNA samples were amplified with primers targeting the V4-V5 hypervariable region (563F/926R) of the 16S rRNA gene (Claesson et al., 2010): forward primer (5' AYTGGGYDTAAAGNG) and reverse primer (5' CCGT CAATTYYTTTRAGTTT). The forward primer was tagged with one of four MID tags so the samples could be combined for sequencing on three plates. Amplification, pooling and 454 sequencing using GS FLX Titanium chemistry were performed by EnGenCore LLC (Greenville, SC, USA). Sequence data from all samples were deposited in the NCBI
Sequence Read Archive (SRA) under Bioproject number PRJNA305617 and are also available online as a USGS data release, http://dx.doi.org/10.5066/F7M32SXM (Kellogg and Goldsmith, 2017).

\section{Bioinformatics and Statistical Analysis}

Analysis of the sequence data was conducted using the bioinformatics packages QIIME 1.8.0 on the Data Intensive Academic Grid (DIAG), a National Science Foundation funded MRI-R2 project \#DBI-0959894, and QIIME 1.9.1 on the Amazon Elastic Compute Cloud (Amazon "EC2") using the QIIME Amazon Machine Image (AMI) (Caporaso et al., 2010b). Our detailed bioinformatics workflow including specific scripts and parameters for each step is included in Supplementary Material.

A total of 1,971,430 raw reads were generated from the 12 individual coral samples. Sequences were screened based on the following quality parameters: sequence length between 200 and $700 \mathrm{bp}$, minimum average quality score of 25 , maximum of one primer mismatch, and maximum of a six homopolymer run (Kunin et al., 2010). The sequences were denoised to reduce the overestimation of operational taxonomic units (OTUs) (Quince et al., 2009; Kunin et al., 2010). This resulted in 1,004,996 sequences total and each individual sample library containing over 40,000 sequences (Table 2). An open-reference method with a 97\% similarity threshold (Rideout et al., 2014) was used to select OTUs in order to not discard sequences that were not a perfect match to the Greengenes reference database (release 13_8; DeSantis et al., 2006). Chimeras were removed and the OTUs picked using usearch61 (Edgar, 2010). Alignment was done with PyNAST (version 1.2.2) (Caporaso et al., 2010a). Representative sequences from each OTU were selected, assigned a taxonomic classification using uclust (Edgar, 2010), and used to generate a phylogenetic tree (Price et al., 2010). Non-bacterial sequences (i.e., Eukarya, Archaea, chloroplast, mitochondria) and absolute singletons (defined as an OTU present only once in the analysis) were removed from the OTU table. Samples were then randomly rarefied to the size of the smallest library $(40,064$ sequences) before diversity metrics were calculated (Gihring et al., 2012).

Phylogenetic Investigation of Communities by Reconstruction of Unobserved States, PICRUSt (Langille et al., 2013) was used to predict the functional gene content of the $L$. pertusa-associated bacterial community by comparing the $16 \mathrm{~S}$ rRNA amplicon data against a database of existing bacterial genomes. Due to PICRUSt input requirements, sequences were processed a bit differently than as described above for the rest of the QIIME analyses: Raw amplicon reads were scanned with a 5-base sliding window and trimmed when the average Phred quality score within this window dropped below 30 (Ewing et al., 1998). Reads with ambiguous bases, homopolymers greater than 10 , or total length less than 100 nucleotides were removed with mothur (Schloss et al., 2009). Chimeric sequences were eliminated with uchime (Edgar et al., 2011). Closed-reference OTUs were picked using QIIME 1.9.1 (Caporaso et al., 2010b) using the Greengenes reference database (release 13_5; DeSantis et al., 2006). Predictive functional profiling of closed-reference OTUs was performed 
TABLE 2 | Alpha diversity analysis of $L$. pertusa coral-associated bacterial communities.

\begin{tabular}{|c|c|c|c|c|c|c|c|c|}
\hline Sample ID & Site & Location & Seq Reads* & OTUs & Chao1 richness & Shannon index & Simpson index & Simpson evenness \\
\hline ROV02Q1 & VK826 & Gulf of Mexico & 47,538 & 296 & 348.50 & 1.73 & 0.45 & 0.006 \\
\hline ROV02Q2 & VK826 & Gulf of Mexico & 147,292 & 158 & 334.65 & 0.87 & 0.19 & 0.008 \\
\hline ROV03Q3 & VK826 & Gulf of Mexico & 111,249 & 166 & 230.57 & 1.75 & 0.43 & 0.010 \\
\hline ROV06Q3 & VK906 & Gulf of Mexico & 40,064 & 101 & 116.81 & 0.98 & 0.26 & 0.013 \\
\hline ROV05Q2 & VK906 & Gulf of Mexico & 65,582 & 712 & 783.02 & 3.76 & 0.74 & 0.005 \\
\hline 3731K3 & VK906 & Gulf of Mexico & 71,832 & 126 & 153.07 & 1.97 & 0.58 & 0.019 \\
\hline ROV08Q3 & WFS1 & Gulf of Mexico & 90,135 & 97 & 108.40 & 1.41 & 0.39 & 0.017 \\
\hline ROV09Q1 & WFS1 & Gulf of Mexico & 50,019 & 94 & 106.00 & 1.61 & 0.56 & 0.024 \\
\hline ROV07Q1 & WFS1 & Gulf of Mexico & 122,278 & 124 & 193.79 & 1.39 & 0.42 & 0.014 \\
\hline 3705K6 & ATL & Atlantic & 135,480 & 117 & 175.80 & 2.23 & 0.69 & 0.027 \\
\hline $3705 \mathrm{KIO}$ & ATL & Atlantic & 74,931 & 526 & 604.63 & 4.26 & 0.85 & 0.012 \\
\hline $3705 \mathrm{~K} 3$ & ATL & Atlantic & 47,200 & 109 & 150.17 & 1.67 & 0.49 & 0.018 \\
\hline
\end{tabular}

*Samples were rarefied to 40,064 sequences before diversity metrics were calculated. Shading to show groups of biological replicates from the same site at a glance.

with PICRUSt 1.0.0-dev, basing functional profiles on KEGG Orthology (Kanehisa et al., 2004). Bioinformatic and statistical consulting on the predictive functional profiling was provided by omics2view.consulting GbR (Kiel, Germany).

Alpha and beta diversity calculations as well as relative abundance summaries were done within QIIME 1.9.1 (Caporaso et al., 2010b). Table 2 contains number of OTUs per sample and alpha diversity metrics including the Chao index (Chao, 1984), Shannon diversity index (Shannon, 1948) and Simpson diversity and evenness indices (Simpson, 1949). To examine differences across samples (beta diversity), three matrices were used based on phylogenetic and taxonomic relationships between sequences. UniFrac measurements were used to evaluate the relative importance of presence/absence of specific taxa within the samples (unweighted UniFrac) vs. the abundance of those taxa (weighted UniFrac) (Lozupone and Knight, 2005). BrayCurtis dissimilarity was also used to compare differences between each sample based on the number of sequences per OTU. These metrics were visualized via principal coordinate analysis (PCoA) using the vegan package (Oksanen et al., 2016) in $\mathrm{R}$ (R Core Team, 2015). Additionally, PRIMER-E (Clarke, 1993) was used to calculate analysis of similarities (ANOSIM) and similarity percentage (SIMPER). Relative abundance bar graphs were prepared in R ( $\mathrm{R}$ Core Team, 2015) using the ggplot2 package (Wickham, 2009).

The core microbiome was analyzed using QIIME with the minimum fraction of samples set at $100 \%$. The 454 libraries from van Bleijswijk et al. (2015) were screening using the SRA BLAST function (Altschul et al., 1990) to query each library for matches to our core OTU sequences. Full-length 16S rRNA gene sequences from Neulinger et al. (2008) that were taxonomically similar to our core OTUs were trimmed to the V4-V5 region and then aligned against our core OTU sequences to check for similarity using ClustalX (Thompson et al., 1997). FASTA files from the six L. pertusa libraries (L1-A, L1-B, L2-A, Lo3-A, Lo3-B, L4-A) available from Meistertzheim et al. (2016)'s Bioproject PRJNA296678 were downloaded and run through the RDP Classifier (Wang et al., 2007) to determine if any bacterial groups similar to our core OTUs were present.

\section{RESULTS}

The four collection sites cover a distance of approximately $1,500 \mathrm{~km}$ as the current flows (from Viosca Knoll in the northeastern Gulf of Mexico, south along the West Florida Shelf, around the State of Florida and north into the Atlantic Ocean; Figure 1). Sequencing results were obtained from 12 individual L. pertusa samples (three biological replicates $\times$ four geographic sites). All samples yielded greater than 40,000 reads (Table 2), with a range of 94-712 OTUs (mean 219, median 125). Shannon Index diversity values ranged from 0.87 to 4.26 (mean 1.97 , median 1.70).

Principal coordinate analysis using weighted UniFrac distances (Lozupone and Knight, 2005) clearly divided the samples by ocean basin, separating the Atlantic from the Gulf of Mexico (Figure 2). Using PRIMER-E (Clarke, 1993), we conducted a one-way analysis using Gulf and Atlantic as factors in an Analysis of Similarities (ANOSIM) and found a significant difference between the samples when the data were square-root transformed $(R=0.525, p=0.032)$, but not when the data were 4 th-root transformed $(R=0.212, p=0.141)$. This indicates that a difference in abundance of dominant taxa rather than a difference in rare taxa is driving the pattern seen in Figure 2. A great deal of within-site variability also was visible, given that biological replicates within a geographic site did not cluster together (Figure 2). Similarity percentages calculated using SIMPER on square-root transformed data showed that the average similarity within Gulf samples was $52.45 \%$, with Novosphingobium OTU 154189 driving nearly $40 \%$ of the similarity. In the Atlantic samples, average similarity was only 38.69 , with Oceanospirillales OTU 356942 responsible for $31 \%$ and Novosphingobium OTU 154189 responsible for $22 \%$ of the similarity. These same two OTUs were the highest contributors toward dissimilarity between Atlantic and Gulf samples, but at a much lower level: the average dissimiliarity was $60.62 \%$ and these OTUs contributed 8.2 and $7.4 \%$, respectively.

Examining the relative abundance at the phylum level (Figure 3), all samples were dominated by Proteobacteria (75-96\%). Other phyla that made up greater than $1 \%$ of total 


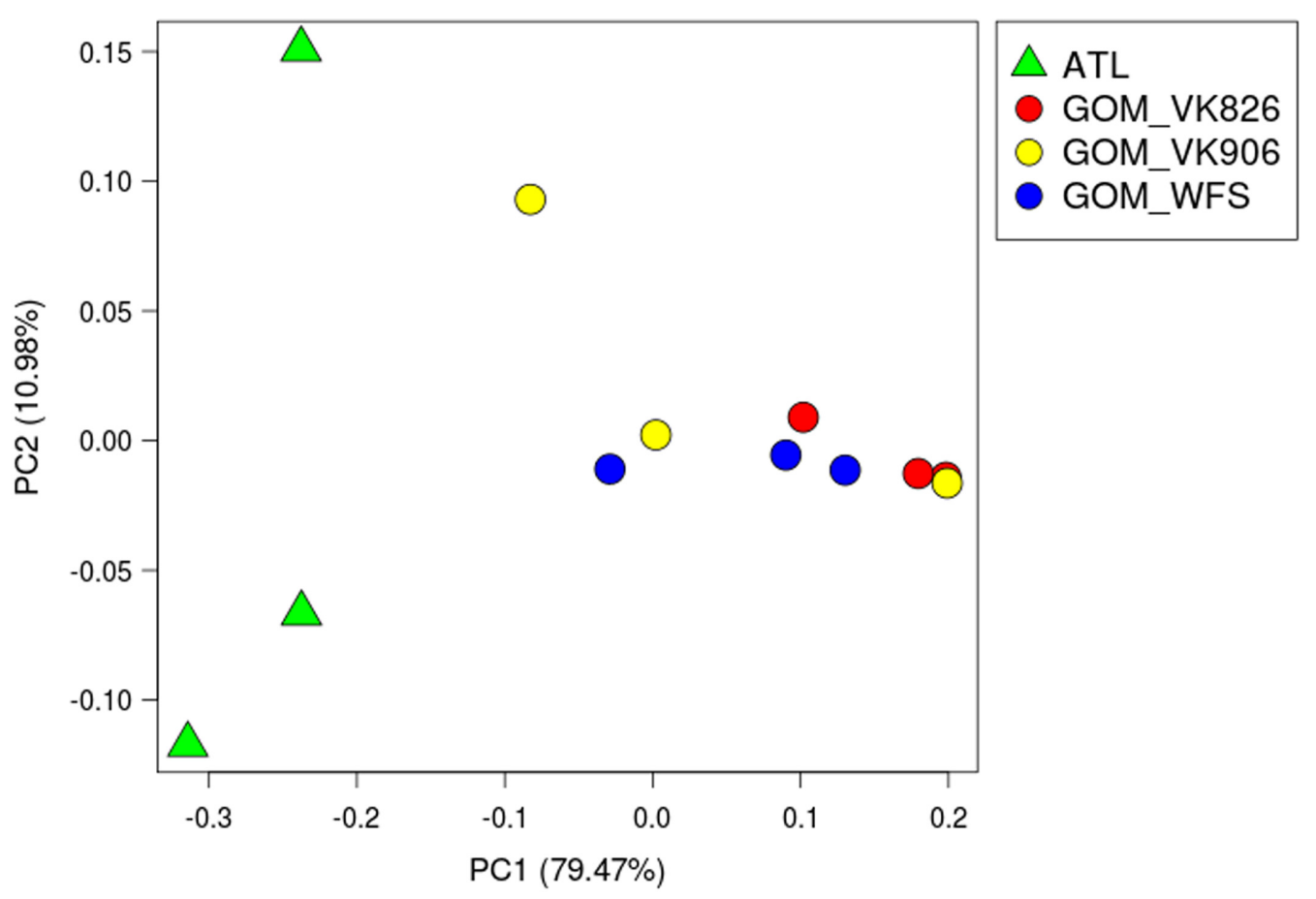

FIGURE 2 | Principal coordinate analysis (PCoA) plot of weighted UniFrac distance. Principal coordinates analysis was used to plot beta diversity of coral-associated bacterial communities using the weighted UniFrac matrix. Green triangles indicate Atlantic samples (site ATL). Circles indicate Gulf of Mexico samples: Red-Viosca Knoll 826; Yellow-Viosca Knoll 906; Blue-West Florida Slope 1.

relative abundance included Acidobacteria, Actinobacteria, Gemmatimonadetes, Planctomycetes, and Verrucomicrobia (Figure 3). At the family level, the majority of the diversity (70-97\% relative abundance) was captured within five families: Pseudonocardiaceae, Pirellulaceae, Rhodobacteraceae, Sphingomonadaceae, and unclassified Oceanospirillales (Figure 4). As predicted by the ANOSIM, differences between the Gulf and Atlantic can be seen to be due to differing relative abundances within these taxa (Figure 4).

Functional predictions in a number of other areas suggest high activity on the part of the L. pertusa-associated bacterial community. In particular, predicted amino acid metabolism for all samples included the biosynthesis of arginine, isoleucine, leucine, lysine, phenylalanine, tryptophan, tyrosine, and valine (Figure 5). Predicted biosynthesis of other secondary metabolites included four antibiotics with three different mechanisms of activity: monobactam (beta lactam), carbapenem (beta lactam), streptomycin (aminoglycoside), and novobiocin (aminocoumarin); in all cases the Atlantic samples were slightly higher than the Gulf of Mexico samples (Supplementary Files). Predicted energy metabolism hinted at chemoautotrophy and nutrient cycling with all samples showing high values for carbon fixation, methane metabolism, nitrogen metabolism, oxidative phosphorylation, and sulfur metabolism (Supplementary Files). Additional predictive profiling data showing functional pathway abundance and completeness by site and by phylum are included in the Supplementary Files.
Sequences were examined to determine if a conserved core bacterial community (Shade and Handelsman, 2012) exists for L. pertusa, here defined as OTUs present in all 12 samples (100\% inclusion). Fifteen OTUs were identified as being held in common (Figure 6), with the core being dominated by an OTU (154189) from the genus Novosphingobium. A second Novosphingobium OTU and three OTUs from the genus Pseudonocardia are the next most prominent taxa. This is striking given that both these bacterial genera are known for their ability to degrade aromatic compounds including hydrocarbons (Notomista et al., 2011; Huang and Goodfellow, 2012). Also present at lower relative abundance were three OTUs that could not be classified, and one OTU each of Alteromonadales, Enterobacteriaceae, and genera Bradyrhizobium, Curtobacterium, Kaistobacter, Propionibacterium, and Sphingomonas (Figure 6). The total core taxa cumulatively make up $19-95 \%$ of the total relative abundance (Figure 7), with a clear difference between the three ATL samples (19-30\%) and the nine Gulf of Mexico samples (52-95\%). Samples from the Atlantic are dominated by a local core (sequences conserved in samples from that site) compared to total core (Figure 7). The lower proportion of Novosphingobium and Pseudonocardia in ATL samples (Figures 4, 7) is likely the driver behind lower functional predictions of xenobiotic biodegradation and metabolism for those samples vs. Gulf of Mexico samples (Figure 8). 


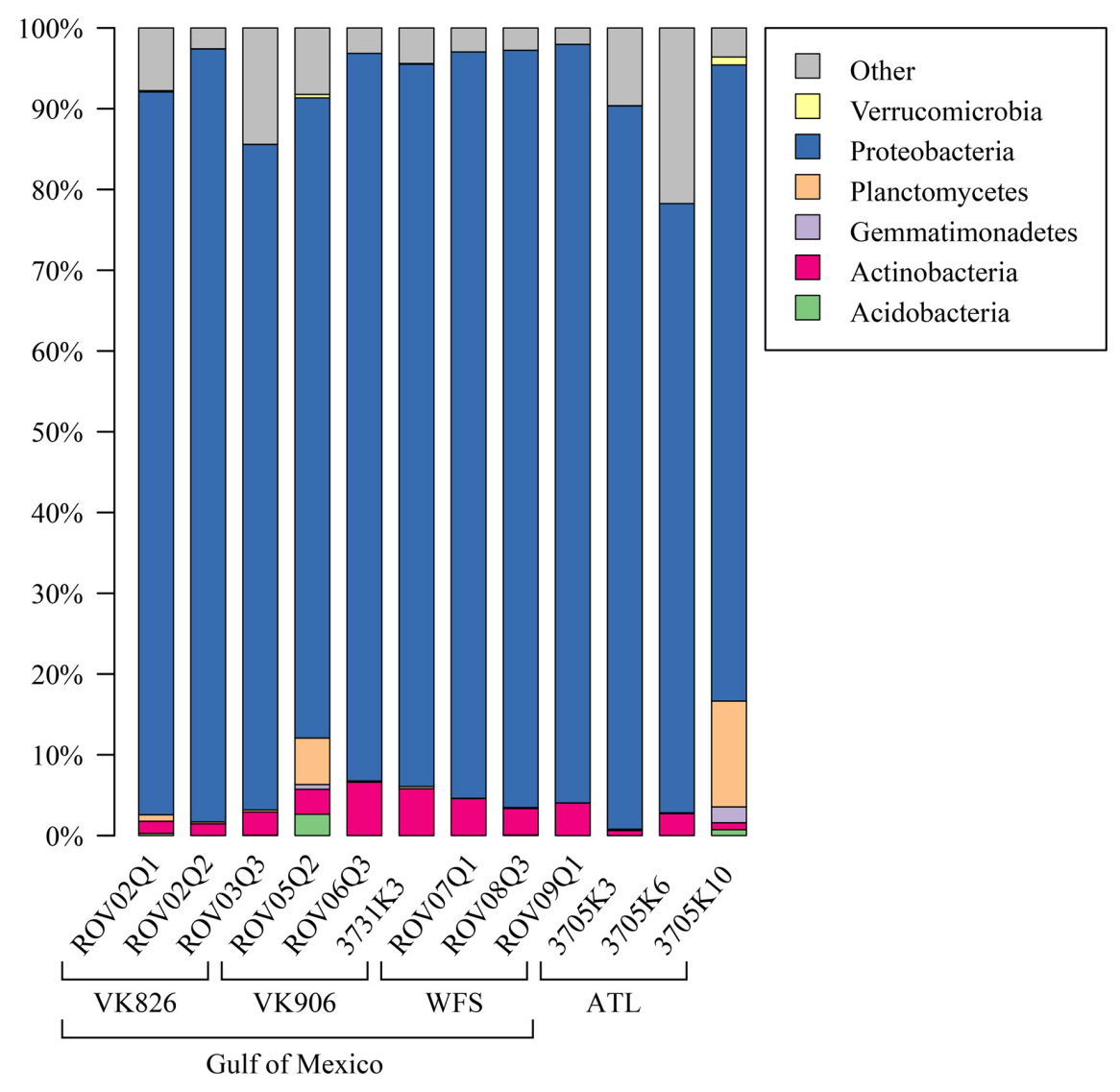

FIGURE 3 | Relative abundance of bacterial phyla in $\mathbf{L}$. pertusa samples. Bacterial phyla present at $\geq 1 \%$ relative abundance in at least one sample. All remaining taxa are summarized under "Other".

\section{DISCUSSION}

Studies on the stability of tropical coral-associated bacterial communities have found that temporal (Hong et al., 2009; Ceh et al., 2011) and geographic (Guppy and Bythell, 2006; Klaus et al., 2007; Hong et al., 2009; Littman et al., 2009; Kvennefors et al., 2010; McKew et al., 2012; Morrow et al., 2012) effects do occur, but that species-specificity can still be detected (Rohwer et al., 2002; Bourne and Munn, 2005; Hong et al., 2009; Kvennefors et al., 2010; McKew et al., 2012; Morrow et al., 2012). All of our samples were collected at the same time of year (August-September), so it is unlikely that we would detect any temporal differences (e.g., linked to surface bloom dynamics). The temperature variation observed across our locations was $7.5-11.0^{\circ} \mathrm{C}$ and this was considered likely to be a primary environmental variable; however, no significant patterns were observed. Similarly, the depth range from 397 to $751 \mathrm{~m}$, while potentially a proxy for other environmental gradients, also did not yield any significant patterns. A population study of L. pertusa found genetic differentiation between corals in the Gulf of Mexico (including our Viosca Knoll sites) and those off the Southeastern United States (including Cape Canaveral collections that overlap our ATL site) (Morrison et al., 2011). The host populations' genetic differences could be linked to the differences seen in the microbiomes between the Gulf and Atlantic sites (Figure 2). Additionally, since our samples included both tissue and mucus bacterial communities, it is possible that some of the inter-sample differences seen (i.e., within a site), reflect different levels of mucus entrainment in each sample.

The mucus of L. pertusa has been shown to include 14 of the 20 main amino acids: alanine, arginine, aspartic acid, glutamic acid, glycine, histidine, isoleucine, leucine, lysine, phenylalanine, serine, threonine, tyrosine, valine (Wagner et al., 2011). Cultured fungi from $L$. pertusa have already been shown to metabolize 6 of these, in addition mucus carbohydrates glucose, mannose, $N$-acetyl glucosamine, galactose, xylose, and fucose (Galkiewicz et al., 2012). Predictive functional analysis suggests the bacterial community is capable of metabolizing all 14 of these amino acids (Figure 5) and many carbohydrates, including amino sugars, nucleotide sugars, fructose, mannose, galactose, and sucrose (Supplementary Files). This suggests the possibility of the microbiome recycling carbon and nitrogen from the coral's mucus.

In addition to capture-feeding on particulates, L. pertusa has been shown to be an opportunist feeder capable of taking up dissolved free amino acids (Gori et al., 2013; Mueller et al., 2014). 


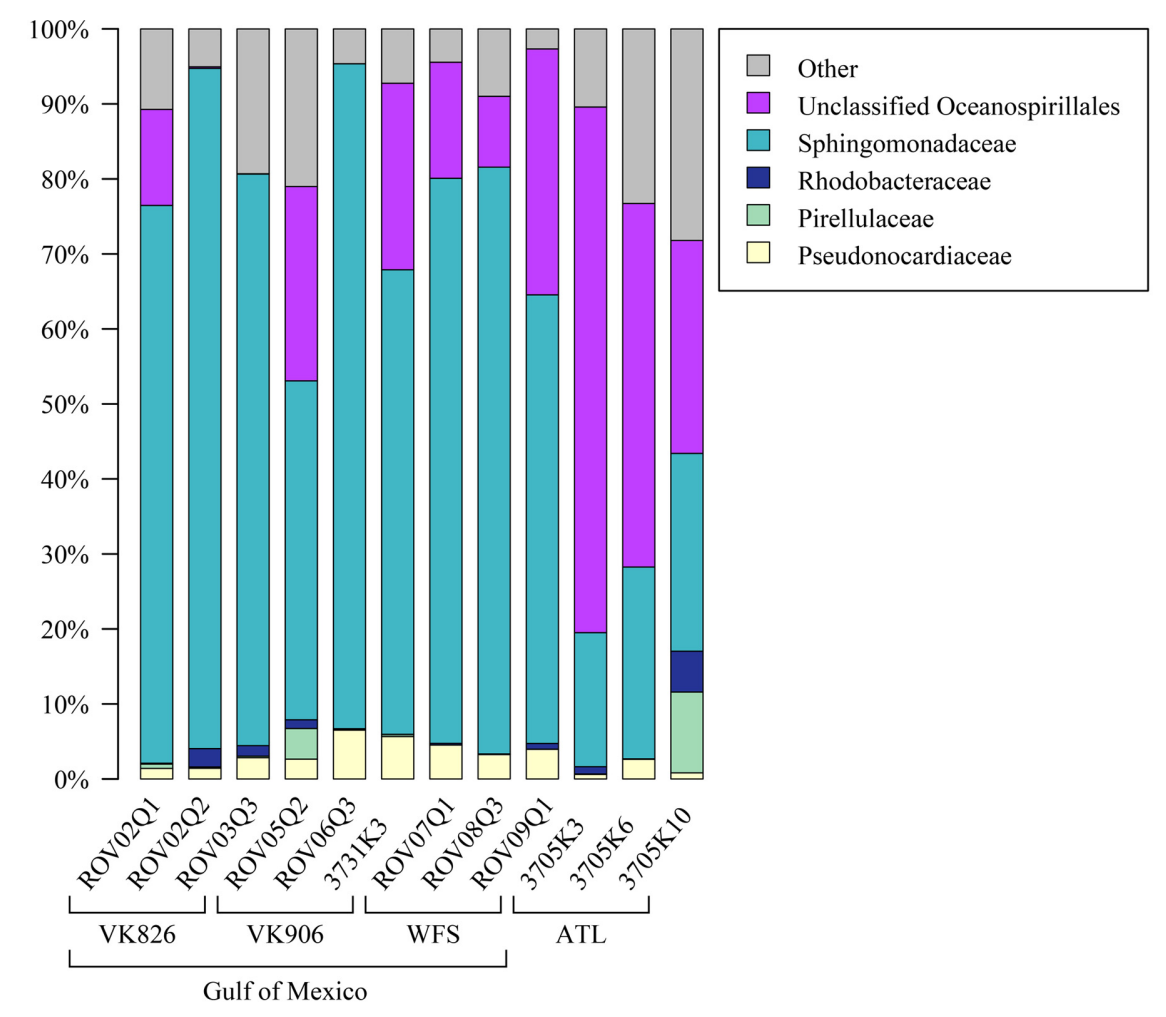

FIGURE 4 | Relative abundance of families (or the lowest identifiable phylogenetic level) in $L$. pertusa samples. Bacterial groups that represent $\geq 1 \%$ of the total taxa. All remaining taxa are summarized as "Other".

This matches well with the bacterial community's above mentioned capacity to metabolize a wide range of amino acids (Figure 5). Functional predictions also suggest that the L. pertusa bacterial community is capable of synthesizing arginine, tyrosine, and 6 of the 9 putatively "essential" amino acids (isoleucine, leucine, lysine, phenylalanine, tryptophan, valine; Figure 5). This, in addition to a high predicted capacity for fatty acid biosynthesis (Supplementary Files), supports recent findings using stable isotopes to prove transfer of fixed nitrogen and inorganic carbon into these tissue components (Middelburg et al., 2015). The chemoautotrophy and nitrogen cycling observed by Middelburg et al. (2015) is further echoed by the high predictive values for energy metabolism by the bacterial community, including carbon fixation, oxidative phosphorylation, and metabolism of methane, nitrogen, and sulfur (Supplementary Files). While the contribution of this chemosynthesis appears to serve only a minor part of $L$. pertusa's metabolic requirements, it may be important enough to shape the bacterial community, resulting in conservation of either specific taxonomic or functional groups.

The Atlantic and Gulf samples were dominated by the same four families and one unclassified order (Figure 4), but with significant differences in relative abundance. The Gulf samples were more enriched in Sphingomonadaceae and Pseudonocardiaceae, whereas the Atlantic samples were dominated by unclassified Oceanospirillales. This translated to Gulf samples containing a higher proportion of the conserved total core, including Novosphingobium and Pseudonocardia OTUs compared to the Atlantic (Figures 6, 7). Both these genera are known to be able to degrade aromatic hydrocarbons (e.g., Notomista et al., 2011; Huang and Goodfellow, 2012). We acknowledge that aromatic hydrocarbon degrading bacteria in general are virtually ubiquitous (e.g., Hazen et al., 2010; Kostka et al., 2011; Ghosal et al., 2016) and their presence is not necessarily specifically related to the presence of hydrocarbons (although presence of hydrocarbons can enrich for degraders; Hazen et al., 2010). However, given that the Gulf of Mexico has many natural hydrocarbon seeps (MacDonald et al., 1990; Roberts et al., 2007) and localized hydrocarbon seepage was observed at Viosca Knoll 826 (Cordes et al., 2006), it is possible that $L$. pertusa colonies in the Gulf maintain a higher abundance of core bacteria that are capable of breaking down these carbon sources (Figure 8). For comparison, neither Novosphingobium nor Pseudonocardia were detected in the microbiomes of four other species of deep-sea corals in the Atlantic (Kellogg et al., 2016; Lawler et al., 2016). However, previous research does not indicate incorporation of seep carbon into these corals (Becker et al., 2009), implying that bacterial action may be to detoxify rather than to provide nutrition.

Pseudonocardia are also known to be antibiotic producers and so another possibility for their core function could be to protect the coral from invading pathogens or to structure the microbiome by preventing overgrowth of certain taxa 


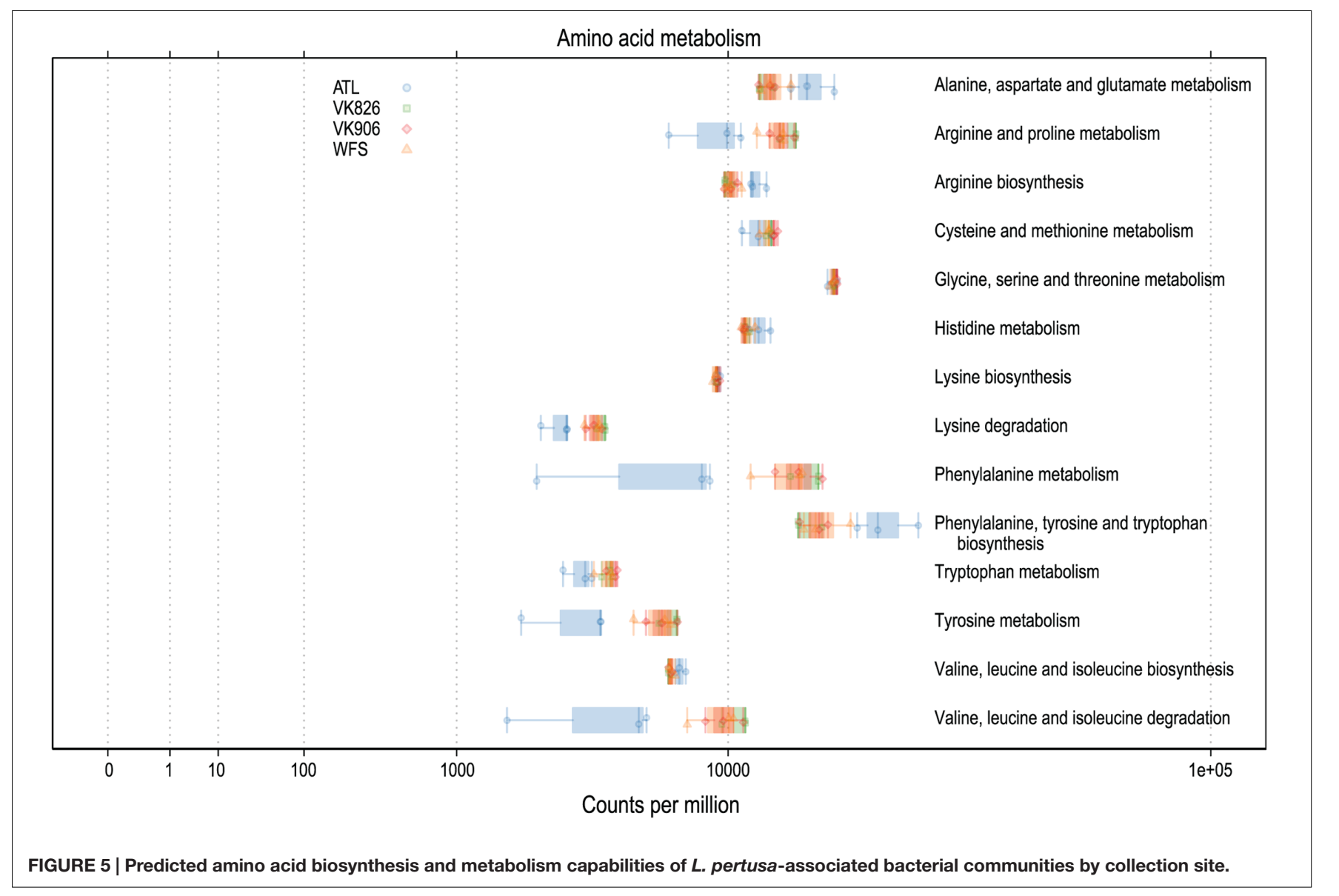

(Zhang et al., 2013). All samples showed relatively high predicted values for production of a number of antibiotics: monobactam, carbapenem, streptomycin, and novobiocin, but in all cases the Atlantic samples were slightly higher (Supplementary Files). While several Gulf of Mexico samples had higher relative abundance of Pseudonocardiaceae (Figure 4), Atlantic samples also contained other actinobacterial species (Actinomyces and Microbacterium) in their local or individual microbiomes (Figure 7) at less than 1\% total relative abundance.

The dominant bacterial phylum detected in L. pertusa was Proteobacteria, which corroborates prior work conducted using clone libraries (Neulinger et al., 2008; Kellogg et al., 2009) as well as pyrosequencing targeting the V1-V3 (Meistertzheim et al., 2016) and V4 (van Bleijswijk et al., 2015) variable regions of the $16 \mathrm{~S}$ rRNA gene. Additional major phyla seen in our dataset have also been previously detected in L. pertusa, but not consistently by all studies; i.e., Acidobacteria (Yakimov et al., 2006; van Bleijswijk et al., 2015; Meistertzheim et al., 2016), Actinobacteria (Neulinger et al., 2008; Galkiewicz et al., 2011; Meistertzheim et al., 2016), Gemmatimonadetes (van Bleijswijk et al., 2015), Planctomycetes (Neulinger et al., 2008; Kellogg et al., 2009; van Bleijswijk et al., 2015; Meistertzheim et al., 2016), and Verrucomicrobia (Neulinger et al., 2008; van Bleijswijk et al., 2015).

Prior clone library and in situ hybridization studies identified mycoplasmas as a component of the L. pertusa microbiome
(Neulinger et al., 2008, 2009; Kellogg et al., 2009), however, neither of the recent pyrosequencing efforts on this coral detected them (van Bleijswijk et al., 2015; Meistertzheim et al., 2016). Our hypotheses were that (a) since van Bleijswijk et al. (2015) only examined mucus, and it was previously shown by fluorescent in situ hybridization (FISH) that the mycoplamas were in the tissue component (Neulinger et al., 2009), that explained their absence in one dataset, and (b) perhaps the low number of sequences examined (446 per sample) by Meistertzheim et al. (2016) was insufficient to detect mycoplasmas. With our greater sequencing depth, we did observe Tenericutes in 7 of 12 samples, but always at less than $1 \%$ relative abundance. Of those samples, 5 contained sequences that were identified to the genus Mycoplasma (ROV02Q1, 3731K3, ROV07Q1, 3705K3, $3705 \mathrm{~K} 10$ ), including at least one replicate from each geographic site. This suggests that while present in this coral, there could be either strong positive selection for mycoplasmal sequences using the clone library protocol (e.g., Kellogg et al., 2009; Gray et al., 2011), or conversely, that there may be negative selection against mycoplasmal sequences in pyrosequencing methods. An alternative (and not mutually exclusive) hypothesis put forward by Meistertzheim et al. (2016) is that bacterial community variations seen between and within L. pertusa colonies are due to sample libraries being dominated by the microbiome of the gut cavity and therefore reflective of the varied and opportunistic 


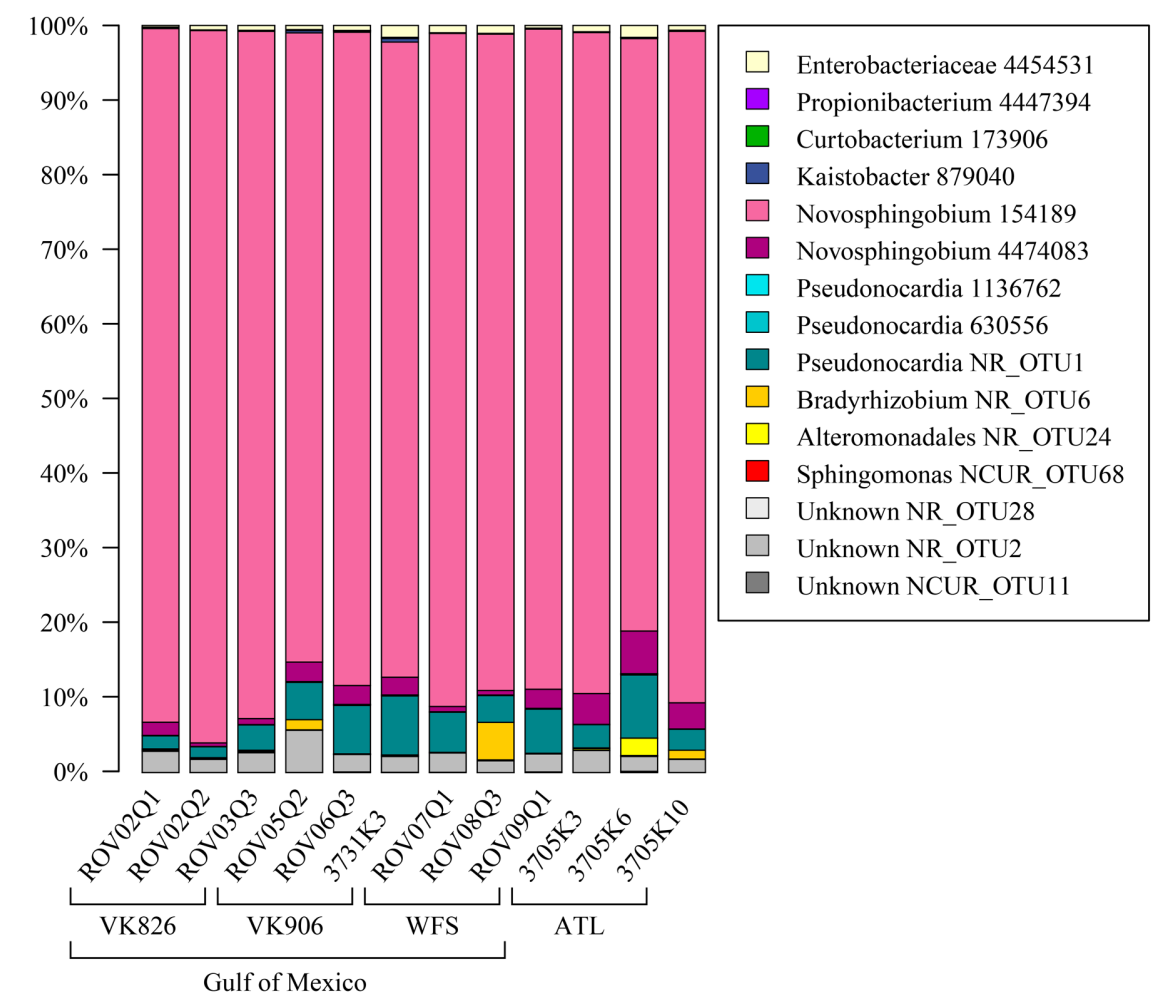

FIGURE 6 | Conserved total core bacterial OTUs in L. pertusa. Relative abundance of the 15 OTUs found to be conserved across all 12 coral samples.

diet of the host. Interestingly, when the Mycoplasma OTU from this study was queried using BLAST (Altschul et al., 1990), it did not closely match to mycoplasmal clones from either the Kellogg et al. (2009) or Neulinger et al. (2008) studies. Instead, it was $92 \%$ similar to mycoplasmal clones from deep-sea bamboo corals (Penn et al., 2006) and 91\% similar to a mycoplasmal clone from the Aleutian gorgonian Cryogorgia koolsae (Gray et al., 2011). This was unexpected because Gray et al. (2011) had constructed a phylogenetic tree based on clone library sequences showing that there were two major clades of coral-associated mycoplasma; one that included gorgonian-associated sequences and one that only included L. pertusa-associated sequences.

Propionibacterium OTU 4447394 makes up a small portion of the conserved core identified in these $L$. pertusa samples. However, because Propionibacterium has been recently identified as a rare but conserved member of shallow and mesophotic tropical corals (Ainsworth et al., 2015; Hester et al., 2016), we investigated it more closely. We found that OTU 4447394 had 99\% identity with $100 \%$ coverage against two Propionibacterium clones from Norwegian fjord L. pertusa (Sequence IDs: AM911348, AM911422; Neulinger et al., 2008) and also against three reads from $L$. pertusa mucus collected on Rockall Bank in the UK (Sequence IDs: SRA:ERR951478.4168.1, SRA:ERR951478.3202.1, SRA:ERR951478.1453.1; van Bleijswijk et al., 2015). This shows that Propionibacterium OTU 4447394 is present in L. pertusa datasets on both sides of the Atlantic. We used BLAST (Altschul et al., 1990) to search this OTU against other deep-sea coral sequences derived using the V4 region, confirming this same sequence in the core of Paramuricea placomus (Kellogg et al., 2016) and in the core of Anthothela sp. (Lawler et al., 2016). In all cases, there was a difference of three single nucleotide insertions (duplications of the prior base) in OTU 4447394 compared to the sequences found outside this study. We were unable to directly compare against 454 sequences from Mediterranean L. pertusa (Meistertzheim et al., 2016) because of differing primer regions. However, when we screened the six L. pertusa libraries available from the Meistertzheim et al. (2016) study by running them through RDP Classifier, 5 of the 6 libraries contained the genus Propionibacterium.

Ainsworth et al. (2015) used FISH to show that Propionibacterium cells were located intracellularly within the photosynthetic dinoflagellates housed by the tropical corals. However, there are no photosynthetic symbionts in L. pertusa, P. placomus, or Anthothela sp. given that these corals were all collected at greater than $300 \mathrm{~m}$ depth, living in darkness. It would be illuminating to conduct similar FISH studies to determine the location of Propionibacterium in deep-sea corals. Further, it would be helpful to be able to compare full-length $16 S$ rRNA sequences (or better yet whole genomes) from Propionibacterium in these deep-sea corals against those in photosynthetic symbiont-bearing corals to determine what roles these apparently ubiquitous symbionts are playing. That said, without FISH or culture-based studies, we cannot absolutely rule 


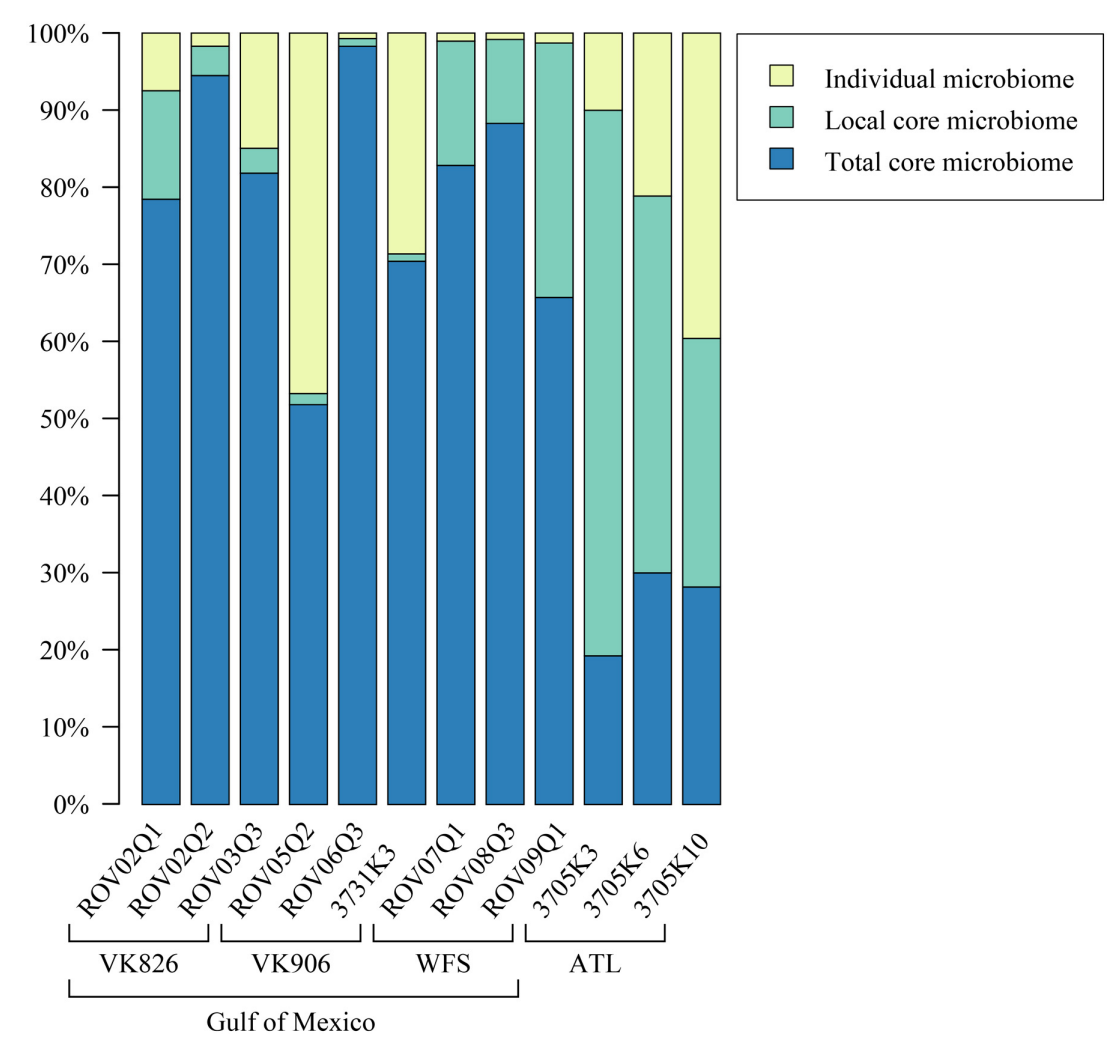

FIGURE 7 | Relative abundance of total core (OTUs found in all samples), local core (OTUs found in all samples from one geographic site), and remaining variable OTUs present in each coral colony.

out the possibility that these Propionibacterium sequences are contaminants from DNA extraction kits (Salter et al., 2014).

In addition to Propionibacterium, the Mediterranean L. pertusa libraries (Meistertzheim et al., 2016) contained several of the other taxa identified as core OTUs in our study. Four libraries contained Alteromonadales (L1-A, Lo3-A, Lo3-B, and L4-A), three libraries contained Enterobacteriaceae (L1-A, L1-B, and L2-A), one library contained Pseudonocardia (L1-B) and one library contained Sphingomonas (L1-A). However, no counterpart was observed in the Mediterranean libraries to our most relatively abundant core OTU, Novosphingobium 154189.

We used BLAST (Altschul et al., 1990) to assess whether any of our core OTUs showed significant sequence matches to other coral-associated studies. Alteromonadales OTU NR_OTU24 was $96 \%$ similar to a clone from coral Tubastraea coccinea (Sequence ID: JF925023.1; Yang et al., 2013) and four clones from a deep-sea black coral (Sequence IDs: DQ395570.1, DQ395572.1, DQ395576.1, DQ395594.1; Penn et al., 2006). Both Novosphingobium total core OTUs in this study were $98 \%$ identical to three deep seawater clones collected near deep-sea corals (Sequence IDs: DQ396195, DQ396202, DQ396285; Penn et al., 2006). Since it is impossible to collect coral samples without exposing them to local seawater, there always exists the possibility that we could detect marine microorganisms. However, coral microbiome samples have consistently been shown to be very different from the bacterial community of the surrounding seawater (e.g., Yakimov et al., 2006; Neulinger et al., 2008; van Bleijswijk et al., 2015) and we would be surprised to find a transient marine microbial signal not overwhelmed by the signal from the tissue community.

A main goal of this study was to determine and characterize the conserved core bacterial community of L. pertusa. However, without having samples from eastern Atlantic and Pacific coral colonies that were processed the same way and sequenced to the same depth, we cannot be certain that the identified core is maintained outside the western Atlantic. For example, Novosphingobium dominated our core and was not detected in other L. pertusa datasets. However, the consistent identification of Propionibacterium in all three next-generation L. pertusa 16S rRNA datasets (this study; van Bleijswijk et al., 2015; Meistertzheim et al., 2016), much like the prior sequence matches between Gulf of Mexico and Norwegian clone library studies (Neulinger et al., 2008; Kellogg et al., 2009) suggests that there are some bacterial phylotypes that are conserved by this coral regardless of geographic provenance.

\section{CONCLUSION}

Our data show that L. pertusa coral colonies in the western Atlantic have a conserved core microbiome of 15 OTUs, 


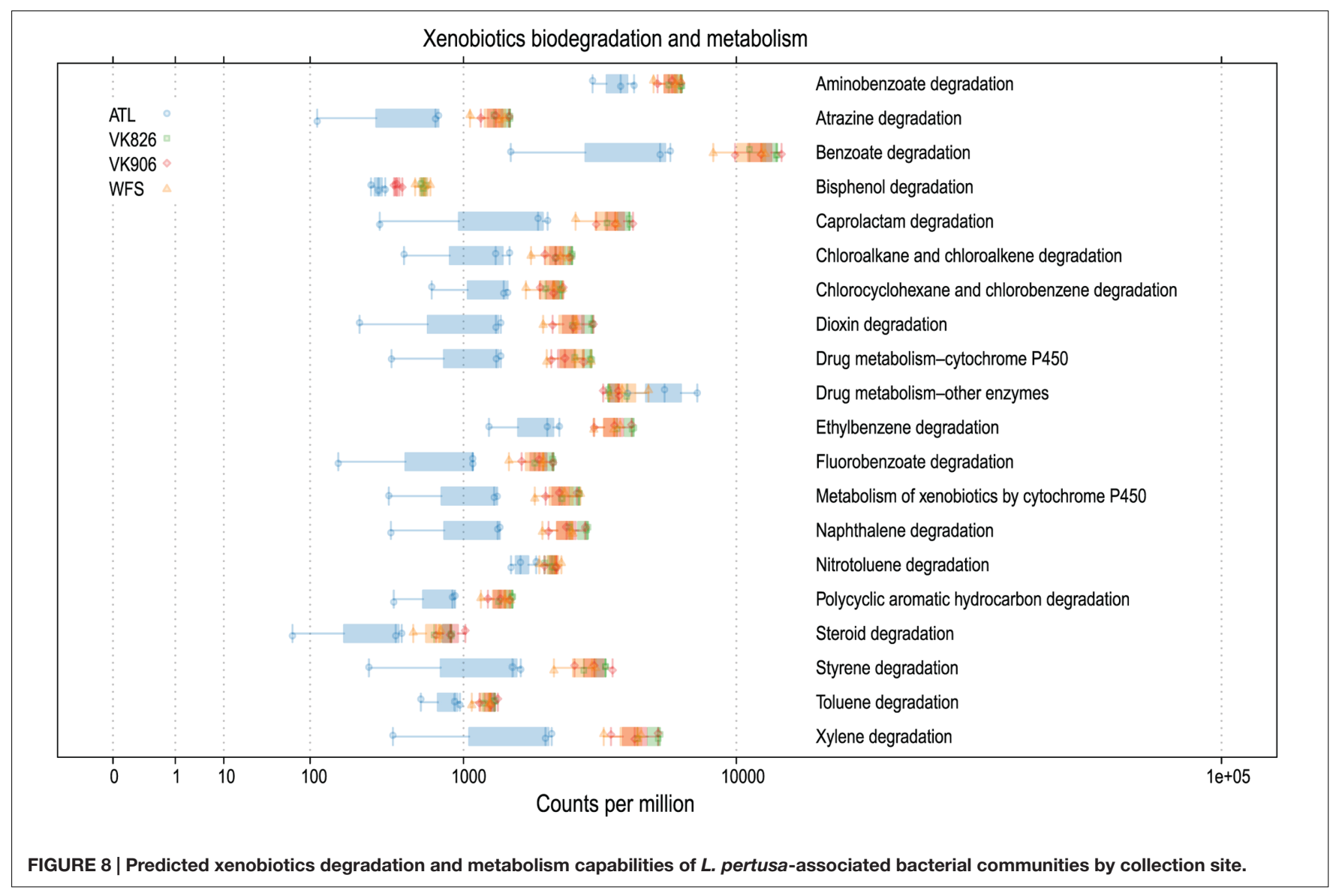

dominated by the genera Novosphingobium and Pseudonocardia. Regional differences were observed between bacterial communities inside the Gulf of Mexico and those in the open Atlantic. Gulf sample communities were primarily composed of the conserved core vs. Atlantic samples that were dominated by locally consistent bacteria not present in the conserved core. Given the dominance of aromatic-hydrocarbon degrading species in the conserved core, we hypothesize that this selection may be driven by the common presence of natural hydrocarbon seepage in the Gulf of Mexico. Mycoplasmal associates previously identified in L. pertusa by clone libraries were not detected. However, a member of the conserved core identified in this study, Propionibacterium OTU 4447394, was matched to sequences derived from L. pertusa in Norway and off Great Britain suggesting a role as a geographically conserved symbiont. Functional predictions generated by PICRUSt align with recent discoveries of chemoautotrophy and nutrient cycling in L. pertusa, highlighting roles of the bacterial community in amino acid biosynthesis and metabolism, carbon fixation, and metabolism of methane, nitrogen, and sulfur.

\section{AUTHOR CONTRIBUTIONS}

CK planned the experimental design, conducted data analysis and wrote the manuscript. DG conducted data analysis and formatted figures. MG performed the DNA extractions and provided text for the Materials and Methods section. All authors edited the manuscript.

\section{FUNDING}

Funding for this project was provided by the U.S. Geological Survey's Ecosystems Mission Area, Environments Program through the Outer Continental Shelf study in support of Bureau of Ocean Energy Management research needs. NOAA provided the ship time for the research cruises. Special thanks to G. Boland and R. Green (BOEM) for their coordination efforts.

\section{ACKNOWLEDGMENTS}

We thank J. P. Galkiewicz for time at sea collecting many of these samples. B. Boynton and G. Range (USGS) created the map figure. The authors also extend appreciation to A. Shade (Michigan State University) and the Explorations in Data Analyses for Metagenomic Advances in Microbial Ecology (EDAMAME) Workshop for critical lessons in workflow organization and bioinformatic tools. Additional thanks are extended to the captains and the crews of the R/V 
Seward Johnson and the Johnson-Sea-Link submersible team as well as the R/V Cape Hatteras and Kraken II ROV team. Any use of trade, firm, or product names is for descriptive purposes only and does not imply endorsement by the U.S. Government.

\section{REFERENCES}

Ainsworth, T. D., Krause, L., Bridge, T., Torda, G., Raina, J.-B., Zakrzewski, M., et al. (2015). The coral core microbiome identifies rare bacterial taxa as ubiquitous endosymbionts. ISME J. 9, 2261-2274. doi: 10.1038/ismej.2015.39

Altschul, S. F., Gish, W., Miller, W., Myers, E. W., and Lipman, D. J. (1990). Basic local alignment search tool. J. Mol. Biol. 215, 403-410. doi: 10.1016/S00222836(05)80360-2

Becker, E. L., Cordes, E. E., Macko, S. A., and Fisher, C. R. (2009). Importance of seep primary production to Lophelia pertusa and associated fauna in the Gulf of Mexico. Deep Sea Res. Part I Oceanogr. Res. Pap. 56, 786-800. doi: 10.1016/j.dsr.2008.12.006

Bourne, D. G., and Munn, C. B. (2005). Diversity of bacteria associated with the coral Pocillopora damicornis from the great barrier reef. Environ. Microbiol. 7, 1162-1174. doi: 10.1111/j.1462-2920.2005.00793.x

Brooke, S., Young, C. M., and Holmes, M. (2007). Biological Characterization and Studies in Continental Shelf Associates. Characterization of Northern Gulf of Mexico Deepwater Hard Bottom Communities With Emphasis on Lophelia Coral. MMS Report No. 2007-044. New Orleans, LA: US Department of Interior, Minerals Management Service, Gulf of Mexico Region, 119-147.

Caporaso, J. G., Bittinger, K., Bushman, F. D., DeSantis, T. Z., Andersen, G. L., and Knight, R. (2010a). PyNAST: a flexible tool for aligning sequences to a template alignment. Bioinformatics 26, 266-267. doi: 10.1093/bioinformatics/btp636

Caporaso, J. G., Kuczynski, J., Stombaugh, J., Bittinger, K., Bushman, F. D., Costello, E. K., et al. (2010b). QIIME allows analysis of high-throughput community sequencing data. Nat. Methods 7, 335-336. doi: 10.1038/nmeth. f.303

Ceh, J., van Keulen, M., and Bourne, D. G. (2011). Coral-associated bacterial communities on Ningaloo Reef, Western Australia. ISME J. 75, 134-144. doi: 10.1111/j.1574-6941.2010.00986.x

Chao, A. (1984). Nonparametric estimation of the number of classes in a population. Scand. J. Stat. 11, 265-270.

Claesson, M. J., Wang, Q., O’Sullivan, O., Greene-Diniz, R., Cole, J. R., Ross, R. P., et al. (2010). Comparison of two next-generation sequencing technologies for resolving highly complex microbiota composition using tandem variable $16 \mathrm{~S}$ rRNA gene regions. Nucleic Acids Res. 38, e200. doi: 10.1093/nar/gkq873

Clarke, K. R. (1993). Non-parametric multivariate analyses of changes in community structure. Aust. J. Ecol. 18, 117-143. doi: 10.1111/j.1442-9993.1993. tb00438.x

Cordes, E. E., Bergquist, D. C., Predmore, B. L., Jones, C., Deines, P., Telesnicki, G., et al. (2006). Alternate unstable states: convergent paths of succession in hydrocarbon-seep tubeworm-associated communities. J. Exp. Mar. Biol. Ecol. 339, 159-176. doi: 10.1016/j.jembe.2006.07.017

Cordes, E. E., McGinley, M. P., Podowski, E. L., Becker, E. L., Lessard-Pilon, S., Viada, S. T., et al. (2008). Coral communities of the deep Gulf of Mexico. Deep Sea Res. Part I Oceanogr. Res. Pap. 55, 777-787. doi: 10.1016/j.dsr.2008.03.005

CSA International Inc. (2007). Characterization of Northern Gulf of Mexico Deepwater Hard-Bottom Communities with Emphasis on Lophelia Coral. OCS Study MMS Report, No. 2007-044. New Orleans, LA: U.S. Department of Interior, Minerals Management Service, Gulf of Mexico OCS Region.

DeSantis, T. Z., Hugenholtz, P., Larsen, N., Rojas, M., Brodie, E. L., Keller, K., et al. (2006). Greengenes, a chimera-checked 16S rRNA gene database and workbench compatible with ARB. Appl. Environ. Microbiol. 72, 5069-5072. doi: 10.1128/AEM.03006-5

Edgar, R. C. (2010). Search and clustering orders of magnitude faster than BLAST. Bioinformatics 26, 2460-2461. doi: 10.1093/bioinformatics/btq461

Edgar, R. C., Haas, B. J., Clemente, J. C., Quince, C., and Knight, R. (2011). UCHIME improves sensitivity and speed of chimera detection. Bioinformatics 27, 2194-2200. doi: 10.1093/bioinformatics/btr381

\section{SUPPLEMENTARY MATERIAL}

The Supplementary Material for this article can be found online at: http://journal.frontiersin.org/article/10.3389/fmicb. 2017.00796/full\#supplementary-material

Emblem, Å., Karlsen, B. O., Evertsen, J., Miller, D. J., Moum, T., and Johansen, S. D. (2012). Mitogenome polymorphism in a single branch sample revealed sequencing of the Lophelia pertusa coral genome. Gene 506, 344-349. doi: 10.1016/j.gene.2012.06.040

Ewing, B., Hillier, L., Wendl, M. C., and Green, P. (1998). Base-calling of automated sequencer traces using phred. I. Accuracy assessment. Genome Res. 8, 175-185. doi: 10.1101/gr.8.3.175

Galkiewicz, J. P., Pratte, Z. A., Gray, M. A., and Kellogg, C. A. (2011). Characterization of culturable bacteria isolated from the cold-water coral Lophelia pertusa. FEMS Microbiol. Ecol. 77, 333-346. doi: 10.1111/j.1574-6941. 2011.01115.x

Galkiewicz, J. P., Stellick, S. H., Gray, M. A., and Kellogg, C. A. (2012). Cultured fungal associates from the deep-sea coral Lophelia pertusa. Deep Sea Res. Part I Oceanogr. Res. Pap. 67, 12-20. doi: 10.1016/j.dsr.2012.05.001

Ghosal, D., Ghosh, S., Dutta, T. K., and Ahn, Y. (2016). Current state of knowledge in microbial degradation of polycyclic aromatic hydrocarbons (PAHs): a review. Front. Microbiol. 7:1369. doi: 10.3389/fmicb.2016.01369

Gihring, T. M., Green, S. J., and Schadt, C. W. (2012). Massively parallel rRNA gene sequencing exacerbates the potential for biased community diversity comparisons due to variable library sizes. Environ. Microbiol. 14, 285-290. doi: 10.1111/j.1462-2920.2011.02550.x

Gori, A., Grover, R., Orejas, C., Sikorski, S., and Ferrier-Pagès, C. (2013). Uptake of dissolved free amino acids by four cold-water coral species from the Mediterranean Sea. Deep Sea Res. Part II Top. Stud. Oceanogr. 99, 42-50. doi: 10.1016/j.dsr2.2013.06.007

Gray, M. A., Stone, R. P., McLaughlin, M. R., and Kellogg, C. A. (2011). Microbial consortia of gorgonian corals from the Aleutian Islands. FEMS Microbiol. Ecol. 76, 109-120. doi: 10.1111/j.1574-6941.2010.01033.x

Guppy, R., and Bythell, J. C. (2006). Environmental effects on bacterial diversity in the surface mucus layer of the reef coral Montastraea faveolata. Mar. Ecol. Prog. Ser. 328, 133-142. doi: 10.3354/meps328133

Hansson, L., Agis, M., Maier, C., and Weinbauer, M. G. (2009). Community composition of bacteria associated with cold-water coral Madrepora oculata: within and between colony variability. Mar. Ecol. Prog. Ser. 397, 89-102. doi: $10.3354 /$ meps08429

Hazen, T. C., Dubinsky, E. A., DeSantis, T. Z., Andersen, G. L., Piceno, Y. M., Singh, N., et al. (2010). Deep-sea oil plume enriches indigenous oil-degrading bacteria. Science 330, 204-208. doi: 10.1126/science.1195979

Hernandez-Agreda, A., Leggat, W., Bongaerts, P., and Ainsworth, T. D. (2016). The microbial signature provides insight into the mechanistic basis of coral success across reef habitats. mBio 7:e560-16. doi: 10.1128/mBio.00560-16

Hester, E. R., Barott, K. L., Nulton, J., Vermeij, M. J. A., and Rohwer, F. L. (2016). Stable and sporadic symbiont communities of coral and algal holobionts. ISME J. 10, 1157-1169. doi: 10.1038/ismej.2015.190

Hong, M.-J., Yu, Y.-T., Chen, C. A., Chiang, P.-W., and Tang, S.-L. (2009). Influence of species specificity and other factors on bacteria associated with the coral Stylophora pistillata in Taiwan. Appl. Environ. Microbiol. 75, 7797-7806. doi: 10.1128/AEM.01418-9

Huang, Y., and Goodfellow, M. (2012). Genus I. Pseudonocardia. Bergey's Manual of Systematic Bacteriology 5(Part B). New York, NY: Springer-Verlag, 1305-1323.

Kanehisa, M., Goto, S., Kawashima, S., Okuno, Y., and Hattori, M. (2004). The KEGG resource for deciphering the genome. Nucleic Acids Res. 32, D277-D280. doi: 10.1093/nar/gkh063

Kellogg, C. A., and Goldsmith, D. B. (2017). Cold-Water Coral Microbiomes (Lophelia pertusa) from Gulf of Mexico and Atlantic Ocean: Raw Data. U.S. Geological Survey Data Release. Available at: http://dx.doi.org/10.5066/ F7M32SXM

Kellogg, C. A., Lisle, J. T., and Galkiewicz, J. P. (2009). Culture-independent characterization of bacterial communities associated with the cold-water coral 
Lophelia pertusa in the northeastern Gulf of Mexico. Appl. Environ. Microbiol. 75, 2294-2303. doi: 10.1128/AEM.02357-8

Kellogg, C. A., Ross, S. W., and Brooke, S. D. (2016). Bacterial community diversity of the deep-sea octocoral Paramuricea placomus. PeerJ 4:e2529. doi: 10.7717/ peerj. 2529

Klaus, J. S., Janse, I., Helkoop, J. M., Sanford, R. A., and Fouke, B. W. (2007). Coral microbial communities, zooxanthellae and mucus along gradients of seawater depth and coastal pollution. Environ. Microbiol. 9, 1291-1305. doi: 10.1111/j.1462-2920.2007.01249.x

Kostka, J. E., Prakash, O., Overholt, W. A., Green, S. J., Freyer, G., Canion, A., et al. (2011). Hydrocarbon-degrading bacteria and the bacterial community response in Gulf of Mexico beach sands impacted by the Deepwater Horizon oil spill. Appl. Environ. Microbiol. 77, 7962-7974. doi: 10.1128/AEM.05402-11

Kunin, V., Engelbrektson, A., Ochman, H., and Hugenholtz, P. (2010). Wrinkles in the rare biosphere: pyrosequencing errors can lead to artificial inflation of diversity estimates. Environ. Microbiol. 12, 118-123. doi: 10.1111/j.1462-2920. 2009.02051.x

Kvennefors, E. C. E., Sampayo, E., Ridgway, T., Barnes, A. C., and HoeghGuldberg, O. (2010). Bacterial communities of two ubiquitous Great Barrier Reef corals reveals both site- and species-specificity of common bacterial associates. PLoS ONE 5:e10401. doi: 10.1371/journal.pone.0010401

Langille, M. G. I., Zaneveld, J., Caporaso, J. G., McDonald, D., Knights, D., Reyes, J. A., et al. (2013). Predictive functional profiling of microbial communities using 16S rRNA marker gene sequences. Nat. Biotechnol. 31, 814-821. doi: $10.1038 /$ nbt.2676

Lawler, S. N., Kellogg, C. A., France, S. C., Clostio, R. W., Brooke, S. D., and Ross, S. W. (2016). Coral-associated bacterial diversity is conserved across two deep-sea Anthothela species. Front. Microbiol. 7:458. doi: 10.3389/fmicb.2016. 00458

Littman, R. A., Willis, B. L., Pfeffer, C., and Bourne, D. G. (2009). Diversities of coral-associated bacteria differ with location, but not species, for three acroporid corals on the Great Barrier Reef. FEMS Microbiol. Ecol. 68, 152-163. doi: 10.1111/j.1574-6941.2009.00666.x

Lozupone, C., and Knight, R. (2005). UniFrac: a new phylogenetic method for comparing microbial communities. Appl. Environ. Microbiol. 71, 8228-8235. doi: 10.1128/AEM.71.12.8228-8235.2005

Lunden, J. J., Georgian, S. E., and Cordes, E. E. (2013). Aragonite saturation states at cold-water coral reefs structured by Lophelia pertusa in the northern Gulf of Mexico. Limnol. Oceanogr. 58, 354-362. doi: 10.4319/lo.2013.58.1.0354

MacDonald, I. R., Guinasso, N. L. Jr., Reilly, J. F., Brooks, J. M., Callender, W. R., et al. (1990). Gulf of Mexico hydrocarbon seep communities: VI. Patterns in community structure and habitat. Geo Mar. Lett. 10, 244-252. doi: 10.1007/ BF02431071

Maxwell, S. (2005). An aquatic pharmacy: the biomedical potential of the deep sea. J. Mar. Educ. 21, 31-32.

McKew, B. A., Dumbrell, A. J., Daud, S. D., Hepburn, L., Thorpe, E., Mogensen, L., et al. (2012). Characterization of geographically distinct bacterial communities associated with coral mucus produced by Acropora spp. and Porites spp. Appl. Environ. Microbiol. 78, 5229-5237. doi: 10.1128/AEM.07764-11

Meistertzheim, A.-L., Lartaud, F., Arnaud-Haond, S., Kalenitchenko, D., Bessalam, M., Le Bris, N., et al. (2016). Patterns of bacteria-host associations suggest different ecological strategies between two reef building cold-water coral species. Deep Sea Res. Part I Oceanogr. Res. Pap. 114, 12-22. doi: 10.1016/ j.dsr.2016.04.013

Middelburg, J. J., Mueller, C. E., Veuger, B., Larsson, A. I., Form, A., and van Oevelen, D. (2015). Discovery of symbiotic nitrogen fixation and chemoautotrophy in cold-water corals. Sci. Rep. 5:17962. doi: 10.1038/ srep17962

Morrison, C. L., Ross, S. W., Nizinski, M. S., Brooke, S., Järnegren, J., Waller, R. G., et al. (2011). Genetic discontinuity among regional populations of Lophelia pertusa in the North Atlantic Ocean. Conserv. Genet. 12, 713-729. doi: 10.1007/ s10592-010-0178-5

Morrow, K. M., Bourne, D. G., Humphrey, C., Botté, E. S., Laffy, P., Zaneveld, J., et al. (2015). Natural volcanic CO2 seeps reveal future trajectories for hostmicrobial associations in corals and sponges. ISME J. 9, 894-908. doi: 10.1038/ ismej. 2014.188

Morrow, K. M., Moss, A. G., Chadwick, N. E., and Liles, M. R. (2012). Bacterial associates of two Caribbean coral species reveal species-specific distribution and geographic variability. Appl. Environ. Microbiol. 78, 6438-6449. doi: 10.1128/ AEM.01162-12

Mortensen, P. B., Hovland, M., Brattegard, T., and Farestveit, R. (1995). Deep water bioherms of the scleractinian coral Lophelia pertusa (L.) at $64^{\circ} \mathrm{N}$ on the Norwegian shelf: structure and associated megafauna. Sarsia 80, 145-158. doi: 10.1080/00364827.1995.10413586

Mueller, C. E., Larsson, A. I., Veuger, B., Middelburg, J. J., and van Oevelen, D. (2014). Opportunistic feeding on various organic food sources by the coldwater coral Lophelia pertusa. Biogeosciences 11, 123-133. doi: 10.5194/bg-11123-2014

Neulinger, S. C., Gärtner, A., Järnegren, J., Ludvigsen, M., Lochte, K., and Dullo, W.-C. (2009). Tissue-associated "Candidatus Mycoplasma corallicola" and filamentous bacteria on the cold-water coral Lophelia pertusa (Scleractinia). Appl. Environ. Microbiol. 75, 1437-1444. doi: 10.1128/AEM. 01781-08

Neulinger, S. C., Järnegren, J., Ludvigsen, M., Lochte, K., and Dullo, W.-C. (2008). Phenotype-specific bacterial communities in the cold-water coral Lophelia pertusa (Scleractinia) and their implications for the coral's nutrition, health, and distribution. Appl. Environ. Microbiol. 74, 7272-7285. doi: 10.1128/AEM. 0177708

Notomista, E., Pennacchio, F., Cafaro, V., Smaldone, G., Izzo, V., Troncone, L., et al. (2011). The marine isolate Novosphingobium sp. PP1Y shows specific adaptation to use the aromatic fraction of fuels as the sole carbon and energy source. Microb. Ecol. 61, 582-594. doi: 10.1007/s00248-0109786-3

Oksanen, J., Blanchet, F. G., Friendly, M., Kindt, R., Legendre, P., McGlinn, D., et al. (2016). vegan: Community Ecology Package. R Package Version 2.4-0. doi: 10.1186/s12866-016-0748- $\mathrm{x}$ Available at: https://cran.r-project.org/package= vegan.

Penn, K., Wu, D., Eisen, J. A., and Ward, N. (2006). Characterization of bacterial communities associated with deep-sea corals on Gulf of Alaska seamounts. Appl. Environ. Microbiol. 72, 1680-1683. doi: 10.1128/AEM.72.2.1680-1683. 2006

Price, M. N., Dehal, P. S., and Arkin, A. P. (2010). FastTree 2 - approximately maximum-likelihood trees for large alignments. PLoS ONE 5:e9490. doi: 10.1371/journal.pone.0009490

Quince, C., Lanzén, A., Curtis, T. P., Davenport, R. J., Hall, N., Head, I. M., et al. (2009). Accurate determination of microbial diversity from 454 pyrosequencing data. Nat. Methods 6, 639-641. doi: 10.1038/NMETH.1361

R Core Team (2015). R: A Language and Environment for Statistical Computing. Vienna: R Foundation for Statistical Computing.

Rideout, J. R., He, Y., Navas-Molina, J. A., Walters, W. A., Ursell, L. K., Gibbons, S. M., et al. (2014). Subsampled open-reference clustering creates consistent, comprehensive OTU definitions and scales to billions of sequences. PeerJ 2:e545. doi: $10.7717 /$ peerj.545

Roberts, H. H., Fisher, C. R., Brooks, J. M., Bernard, B., Carney, R. S., Cordes, E., et al. (2007). Exploration of the deep Gulf of Mexico slope using DSV Alvin: Site selection and geographic character. Gulf Coast Assoc. Geol. Soc. Trans. 57, 647-659.

Rohwer, F., Seguritan, V., Azam, F., and Knowlton, N. (2002). Diversity and distribution of coral-associated bacteria. Mar. Ecol. Prog. Ser. 243, 1-10. doi: $10.3354 /$ meps 243001

Rubio-Portillo, E., Santos, F., Martínez-García, M., de los Ríos, A., Ascaso, C., Souza-Egipsy, V., et al. (2016). Structure and temporal dynamics of the bacterial communities associated to microhabitats of the coral Oculina patagonica. Environ. Microbiol. 18, 4564-4578. doi: 10.1111/1462-2920.13548

Salter, S. J., Cox, M. J., Turek, E. M., Calus, S. T., Cookson, W. O., Moffatt, M. F., et al. (2014). Reagent and laboratory contamination can critically impact sequence-based microbiome analyses. BMC Biol. 12:87. doi: 10.1186/s12915014-0087-z

Schloss, P. D., Westcott, S. L., Ryabin, T., Hall, J. R., Hartmann, M., Hollister, E. B., et al. (2009). Introducing mothur: open-source, platform-independent, community-supported software for describing and comparing microbial communities. Appl. Environ. Microbiol. 75, 7537-7541. doi: 10.1128/AEM. 01541-09

Schöttner, S., Hoffmann, F., Wild, C., Rapp, H. T., Boetius, A., and Ramette, A. (2009). Inter- and intra-habitat bacterial diversity associated with cold-water corals. ISME J. 3, 756-759. doi: 10.1038/ismej.2009.15 
Shade, A., and Handelsman, J. (2012). Beyond the Venn diagram: the hunt for a core microbiome. Environ. Microbiol. 14, 4-12. doi: 10.1111/j.1462-2920.2011. 02585.x

Shannon, C. (1948). A mathematical theory of communication. Bell Syst. Tech. J. 27, 379-423. doi: 10.1002/j.1538-7305.1948.tb01338.x

Simpson, E. (1949). Measurement of diversity. Nature 163:688. doi: 10.1038/ $163688 \mathrm{a} 0$

Sunagawa, S., Woodley, C. M., and Medina, M. (2010). Threatened corals provide underexplored microbial habitats. PLOS ONE 5:e9554. doi: 10.1371/journal. pone.0009554

Thompson, J. D., Gibson, T. J., Plewniak, F., Jeanmougin, F., and Higgins, D. G. (1997). The CLUSTAL X windows interface: flexible strategies for multiple sequence alignment aided by quality analysis tools. Nucleic Acids Res. 24, 4876-4882. doi: 10.1093/nar/25.24.4876

van Bleijswijk, J. D. L., Whalen, C., Duineveld, G. C. A., Lavaleye, M. S. S., Witte, H. J., and Mienis, F. (2015). Microbial assemblages on a cold-water coral mound at the SE Rockall Bank (NE Atlantic): interactions with hydrography and topography. Biogeosciences 12, 4483-4496. doi: 10.5194/bgd-12-1509-2015

van de Water, J. A. J. M., Melkonian, R., Voolstra, C. R., Junca, H., Beraud, E., Allemand, D., et al. (2016). Comparative assessment of Mediterranean gorgonian-associated microbial communities reveals conserved core and locally variant bacteria. Microb. Ecol. 73, 466-478. doi: 10.1007/s00248-016-0858-x

Wagner, H., Purser, A., Thomsen, L., Jesus, C. C., and Lundälv, T. (2011). Particulate organic matter fluxes and hydrodynamics at the Tisler cold-water coral reef. J. Mar. Syst. 85, 19-29. doi: 10.1016/j.jmarsys.2010.11.003

Wang, Q., Garrity, G. M., Tiedje, J. M., and Cole, J. R. (2007). Naive Bayesian classifier for rapid assignment of rRNA sequences into the new bacterial taxonomy. Appl. Environ. Microbiol. 73, 5261-5267. doi: 10.1128/AEM. 00062-07

Wickham, H. (2009). ggplot2: Elegant Graphics for Data Analysis. New York, NY: Springer-Verlag. doi: 10.1007/978-0-387-98141-3
Williams, B., Risk, M. J., Ross, S. W., and Sulak, K. J. (2006). Deep-water antipatharians: proxies of environmental change. Geology 34, 773-776. doi: 10.1130/G22685.1

Yakimov, M. M., Cappello, S., Crisafi, E., Trusi, A., Savini, A., Corselli, C., et al. (2006). Phylogenetic survey of metabolically active microbial communities associated with the deep-sea coral Lophelia pertusa from the Apulian plateau, Central Mediterranean Sea. Deep Sea Res. 53, 62-75. doi: 10.1016/j.dsr.2005. 07.005

Yang, S., Sun, W., Zhang, F., and Li, Z. (2013). Phylogenetically diverse denitrifying and ammonia-oxidizing bacteria in corals Alcyonium gracillimum and Tubastraea coccinea. Mar. Biotechnol. 15, 540-551. doi: 10.1007/s10126013-9503-6

Zaneveld, J. R., Burkepile, D. E., Shantz, A. A., Pritchard, C., McMinds, R., Payet, J. P., et al. (2016). Overfishing and nutrient pollution interact with temperature to disrupt coral reefs down to microbial scales. Nat. Commun. 7:11833. doi: $10.1038 /$ ncomms11833

Zhang, X.-Y., He, F., Wang, G.-H., Bao, J., Xu, X.-Y., and Qi, S.-H. (2013). Diversity and antibacterial activity of culturable actinobacteria isolated from five species of the South China Sea gorgonian corals. World J. Microbiol. Biotechnol. 29, 1107-1116. doi: 10.1007/s11274-013-1279-3

Conflict of Interest Statement: The authors declare that the research was conducted in the absence of any commercial or financial relationships that could be construed as a potential conflict of interest.

Copyright (c) 2017 Kellogg, Goldsmith and Gray. This is an open-access article distributed under the terms of the Creative Commons Attribution License (CC BY). The use, distribution or reproduction in other forums is permitted, provided the original author(s) or licensor are credited and that the original publication in this journal is cited, in accordance with accepted academic practice. No use, distribution or reproduction is permitted which does not comply with these terms. 